\title{
Assessment of physical activity, and physical fitness, in population surveys
}

\begin{abstract}
As the contributions of exercise to health and well being are becoming increasingly recognised, ${ }^{1-3}$ interest in health promotion has stimulated demand for practical methods of assessment of physical activity patterns. Unfortunately, no methods are generally accepted, so it has become the custom for investigators to devise their own-often with scant reference to validity, and still less to comparability with other studies. Walking, for example, can range from gentle strolling to striding at a brisk pace. ${ }^{4}$ Yet frequently all walking will be graded as light activity. The manner in which walking is treated can, therefore, substantially affect individual classification for total activity and for aerobic exercise, since walking is the only sustained aerobic activity that is at all common in industrialised societies. The same applies to other important sources of exercise. Gardening, the commonest hobby involving physical "work" in this country, can vary in energy expenditure from pruning roses to heavy manual labour in a vegetable allotment, yet it is commonly graded as "moderate" activity.
\end{abstract}

\section{Physiology of exercise}

Two principal dimensions of physical activity should be captured in populations surveys. These are (1) total physical activity, which is equivalent to energy output-with energy intake this controls the body weight, affecting also body composition, ie, the muscle to fat ratio; (2) aerobic exercise, which involves the dynamic, rhythmic contraction/relaxation of large muscle groups. When sustained and performed more energetically than is customary for the individual, this will have cardiovascular training (conditioning) effects, improving physical fitness-the capacity for physical work and movement. Aerobic exercise also enhances a range of metabolic functions, such as the lipid profile, and insulin/glucose dynamics.

Adequate data on (1) and (2) will also provide accounts of two other dimensions of physical activity. These are (3) muscle contraction in dynamic exercise (isotonic effort) or against resistance (isometric effort) which increases muscle strength and endurance, again if more vigorous than is customary; and (4) weight bearing exercise such as walking which strengthens bones, and gives some protection against osteoporosis and fracture. Similarly, the movement of joints through their range maintains joint flexibility.

Elements of all of these are involved in the growth and development of children, and in mobility and independence of the elderly. They enhance the self image, as people feel better, and they can afford some relief in anxiety and depression. ${ }^{1-3}$

Exercise intensity and quantity have traditionally been expressed as kilocalories per minute, but MET, ie, multiples of resting oxygen consumption, ${ }^{5}$ are now generally preferred.
One MET represents the energy expended in one minute by a person seated at rest, and is roughly equal to $1 \mathrm{kcal} / \mathrm{min}$, or 1 $\mathrm{kcal} / \mathrm{kg}$ body weight/hour.

Three grades of intensity may usefully be categorised (table). Both individual basal metabolism and the energy output in specific activities vary, so broad averages only are available. ${ }^{4-7}$ In addition, information may be gathered on sweating and hard breathing indicating exertion that requires over half of the individual's functional range of oxygen uptake and heart rate. This is exercise near the upper level that can be maintained. In the unfit, these symptoms may of course be induced by activity which would be considered moderate, or even light, by fitter individuals. The crux of it is that it is vigorous activity for the given individual. This is an important distinction for both epidemiology ${ }^{4}$ and health education.

\begin{tabular}{|c|c|c|c|}
\hline Grade & METS & $\mathrm{kcal} / \mathrm{min}$ & Examples \\
\hline Light & $1-3$ & $1-4$ & $\begin{array}{l}\text { Walking < } 3 \mathrm{mph} \\
\text { Bowling } \\
\text { Hoeing } \\
\text { Electrical repairs }\end{array}$ \\
\hline Moderate & $>3-6$ & $5-7$ & $\begin{array}{l}\text { Walking 3-4 mph } \\
\text { Golf } \\
\text { Lawn mowing } \\
\text { Painting/wallpapering }\end{array}$ \\
\hline Vigorous & $>6$ & $>7$ & $\begin{array}{l}\text { Walking >4 mph } \\
\text { Swimming } \\
\text { Heavy digging } \\
\text { Concreting }\end{array}$ \\
\hline
\end{tabular}

The amount of exercise an individual performs is clearly also necessary to index. Data on duration and frequency can be combined with those on intensity to permit the totalling of individual energy expenditure by daily, weekly, or monthly averages. Calculating total energy expenditure will depend upon individual characteristics, in particular body weight, since the obese require up to $50 \%$ more energy for a given level of activity.

\section{Occupational and leisure time physical activity}

While manual work continues to decline, it remains an important element both of total activity and vigorous activity in the minority involved. Among these, its contribution to overall physical activity increases as middle age advances and participation in recreational activity declines.

For most purposes the only information on occupational activity available will be standard job classifications, ${ }^{5}$ adapted to local requirements. Leisure time physical activity (LTPA) 
includes all activity apart from work. It takes three main forms ${ }^{4}$ :

(1) Sports, games, and "keep-fit" exercises.

(2) Getting about: walking, cycling, stair climbing.

(3) Housework; home making. Recreational "work" in and about the house (DIY), the garden, and on the car.

RECALL QUESTIONNAIRES 15 8-10

These constitute the usual method of assessing physical activity in population studies, when the objective is to learn about the behaviour patterns of different sections of the adult population. Aetiological research may be able to use other methods, such as diaries and even instrumental techniques: the pedometer most popularly, ${ }^{11}$ with telemetry offering the greatest promise. The latter can record in a socially acceptable manner the heart rate responses to physical activity, minute by minute, for prolonged periods. ${ }^{12}$

Questionnaires can be self completed or interviewer completed, depending on resources, the educational level of the population, the heterogeneity in types of physical activity undertaken by the population studied and the detail required. Four week recall is customary, though one week is adequate and more reliable for walking.

In general, the information gathered is more reliable if check lists of actual behaviours are presented (eg, strolling at an easy pace, singles tennis), with the opportunity for personal additions. This is preferable to the recall of activities broadly categorised as "vigorous", "moderate", and "light" activity. Check lists can be expanded into physical activity histories, which assess activities over longer periods, often a full year. This has the advantage of not being dependent upon the time of year during data collection; for seasonal activities, of course, short term recall questionnaires can be highly unreliable.

In addition, the individual responses to the activities in terms of sweating or hard breathing can be recorded. This will permit two modes of analysis: (1) estimates of absolute energy expenditure; (2) activities vigorous for the particular individual.

\section{SHORT CUTS}

There is increasing interest in developing brief or even single question instruments that will classify individuals with sufficient precision for levels of activity or of fitness. ${ }^{13}$ None have yet been validated in a United Kingdom population.

\section{Physical fitness or physical activity? ${ }^{15-10}$}

Measurement of some component of physical fitness is an alternative approach to indexing physical activity patterns. In the field of coronary heart disease epidemiology, fitness can be seen as a biological marker or mediator of a behaviour, exercise participation. Physical fitness stands in the same relationship to exercise as blood cholesterol levels to components of diet. Unfortunately, academic reviewers, as well as the designers of health education literature, have tended to collapse exercise and physical fitness into one category, so obscuring the obvious distinction between the two.

Recently there have been attempts to increase terminological rigour in this area. A US conference ${ }^{8}$ defined physical activity as "any bodily movement produced by skeletal muscles that results in energy expenditure." Physical activity is, by definition, a behaviour. Physical fitness, on the other hand, is "a set of attributes that people have or achieve that relates to the ability to perform physical activity." Physical fitness is thus an index of biological capacity. Of the measurable components of fitness, two have been studied in detail: (1) the ability of the circulatory and respiratory systems to supply fuel during physical activity and to eliminate fatigue products; and (2) body composition, principally the relative amounts of muscle, fat (and bone) of the body.
Body composition has been much investigated, but is not exclusively, or even mainly, a measure of biological capacity. Cardiorespiratory power has been the main component of physical fitness measured in population studies, generally in terms of maximum oxygen uptake. This reflects the maximum functional capacity of the integrated performance of the heart, lungs, vascular system, and muscle tissue, and is a measure of the maximum physical activity which can be sustained while aerobic replenishment of muscle high energy phosphates can occur. A workshop convened by the International Biological Programme (IBP) in 1967 selected maximum oxygen uptake $\left(\mathrm{VO}_{2} \mathrm{max}\right)$ as an appropriate international reference standard. ${ }^{14}$

\section{DETERMINANTS OF PHYSICAL FITNESS ${ }^{1} 67$}

If $\mathrm{VO}_{2} \mathrm{max}$ is to be used as a measure of fitness in surveys, it is important to understand the relative contributions of genetic endowment and environmental (including behavioural) influences in its determination. Considerable controversy has surrounded this question, which is crucial if public health recommendations are to be based upon studies of physical fitness.

Åstrand's comment that "anyone interested in winning Olympic gold medals must select his parents very carefully"15 illustrates the assumption that $\mathrm{VO}_{2} \max$ has a strong genetic component. Frequently quoted studies which purport to demonstrate that $\mathrm{VO}_{2} \max$ is almost entirely genetically determined were performed on populations of young children, with little variance in either physical activity or $\mathrm{VO}_{2}$ max. When variation in non-genetic factors is limited, and they have had little time to exert themselves, non-genetic factors will, of course, account for only a small component in the variance. In more diverse populations, the contribution of genetic endowment to the $\mathrm{VO}_{2} \max$ distribution is more modest, ${ }^{16}$ being of the same order as the heredity contribution to blood cholesterol levels. ${ }^{17}$

The contribution of physical activity in determining $\mathrm{VO}_{2} \mathrm{max}$ levels is demonstrated in training studies, in which increased activity results in some increase in $\mathrm{VO}_{2} \mathrm{max}$ levels. Studies relating questionnaire data regarding physical activity to measured fitness have reported correlations between total leisure time physical activity and fitness ranging from near zero to over $0 \cdot 6 .{ }^{18}$ This range reflects both the variability in the quality of questionnaires and the fact that, as seen, only activity above customary intensity for the individual, and dynamic aerobic activity at that, will have a cardiorespiratory training effect. The proportion of LTPA which falls into this category will be different in different populations.

MEASUREMENT OF PHYSICAL FITNESS ${ }^{15-10}$

The direct measurement of $\mathrm{VO}_{2} \mathrm{max}$ is seen as the gold standard, ${ }^{14}$ depending upon the fact that as subjects increase their power output, a plateau of oxygen consumption is reached after which any further power increase occurs without increase in oxygen uptake. $\mathrm{VO}_{2} \mathrm{max}$ is measured in litres of oxygen consumed per minute. For competently administered tests the day to day variation in directly measured $\mathrm{VO}_{2} \max$ is around $5 \%$, of which some is experimental error. Direct measurement of $\mathrm{VO}_{2} \mathrm{max}$ in field studies is, however, contraindicated by both technical and safety considerations.

Submaximal tests have, therefore, been developed which do not require the same degree of exertion or generate appreciable risk. The general principle of these tests is that heart rate can be used as a marker of the relative effort level of an activity. The assumption is that heart rate and oxygen uptake are linearly related; hence if oygen uptake and heart rate are measured at a submaximal exercise level, the maximum oxygen uptake can be estimated by extrapolating to the maximal heart rate of the subject. ${ }^{671415}$ 
This assumption introduces two problems. First, maximum heart rate must in theory be known for the individual. Obtaining maximum heart rates would require maximum exertion and thus cancel the advantage of submaximal tests. Population values for maximum heart rate according to age have, therefore, been used for the purposes of extrapolation. For a population the standard deviation of maximum heat rate is 10 beats $/ \mathrm{min}^{15}$ and extrapolation to this value introduces error contingent upon it.

The second problem is the less than perfectly linear relationship between oxygen uptake and heart rate. The alinearity tends to be greatest at the top and bottom ends of $\mathrm{VO}_{2} /$ heart rate plots, heart rate being lower than suggested by a linear relationship at low $\mathrm{VO}_{2}$ values and higher at near maximum levels of $\mathrm{VO}_{2}$. Extrapolation from low heart rates would overestimate true $\mathrm{VO}_{2} \max$; so submaximal tests attempt extrapolation from the linear part of the heart rate $/ \mathrm{VO}_{2}$ relationship, between 120 and 170 beats $/ \mathrm{min}$.

A further simplification, avoiding the necessity for complex equipment, is to measure workload (eg, on a cycle ergometer), as a proxy for oxygen uptake. This relies upon (1) a fixed rate of oxygen consumption per unit of internal work, and (2) an accurate way of measuring such work. The failure especially of the second of these assumptions, however, adds further error to the prediction of $\mathrm{VO}_{2} \max$. The result is that the standard error of the estimate for predicted values has generally been found to lie between $10^{\circ}{ }_{0}$ and $15^{\circ}$ o of the population mean value. The $95 \%$ tolerance interval for a test-ie, the range in which the true $\mathrm{VO}_{2} \max$ will lie in $95^{\circ}$ of cases with a given predicted value-will therefore be approximately $\pm 25^{\circ} \%$ of the predicted value. With a population coefficient of variation for $\mathrm{VO}_{2} \mathrm{max}$ of $30^{\circ}$ o this means that in $5^{\circ}$ of cases the predicted value will be almost one population standard deviation-or even more-from the actual value. ${ }^{1671415}$

\section{Validity and repeatability}

Whatever the instrument that is adopted, assessment of its validity, physiological and behavioural, is unlikely to be feasible outside specific research situations. But in such an uncertain field, tests of repeatability are highly desirable, indeed essential good practice.

\section{Conclusions}

Assessment of physical activity and/or physical fitness in population surveys is frequently required. While it may be anticipated that telemetry will increasingly be used as a principal, or adjuvant, method, it is unlikely to be available for many situations. In the study of exercise in relation to the incidence of coronary heart disease, a limited but important issue, it may be supposed that measures of cardiovascular fitness eventually may replace assessments of activity. There are some indications that fitness is a more powerful predictor of the disease. ${ }^{19}$ Moreover, it is the exercise that improves fitness, aerobic exercise, that apparently is protective. ${ }^{4}$
Methods for measuring cardiorespiratory fitness with acceptable precision in population surveys, but which require lower levels of technology than those currently in use, are urgently required. For many purposes, physical activity questionnaires will continue to be the mainstay of this enterprise. Since adequate physical activity histories require tailoring to the population in which they will be used, no "off the peg" model can be recommended for general use in an unmodified form. Adaptation of existing questionnaires to local circumstances should follow field testing of the instrument. Claims made for rapid assessment methods-such as single questions-should be treated with scepticism until adequately assessed. In particular, with a behaviour as socially conditioned as exercise, the possibility that such simple items are merely proxies for many other factors related to social position should be considered.

G DAVEY SMITH

J N MORRIS

1 Bouchard C, Shephard RJ, Stephens T, Sutton JR, McPherson BD, eds Exercise, fitness and healt h: a consensus of current knowledge. Champaign, IL, USA: Human Kinetics Books, 1990. (This includes an invaluable collection of papers on the assessment of physical activity and fitness by an international panel.

2 Fentem PH, Bassey EJ, Turnbull N. The new case for exercise. London: Health Education Authority and Sports Council, 1988.

3 Royal College of Physicians: Medical aspects of exercise: benefits and risks. London: Royal College of Physicians, 1991

4 Morris JN, Clayton DG, Everitt MG, Semmence AM, Burgess EH. Exercise in leisure-time: coronary attack and death rates. Br Heart $\mathcal{F} 1990$; 63: 325-34.

5 Wilson PWF, Paffenburger RS, Morris JN, Havlik RJ. Assessment methods for physical activity and physical fitness in population studies. Am Heart $\mathcal{f}$ 1986; 11: 1177-92. 6 McArdle WD, Katch FI. Exercise physiology, 2nd ed. Philadelphia: Lea and

Pollock ML, Wilmore JH. Exercise in health and disease, 2nd ed. Pollock ML, Wilmore JH. Exercise
Philadelphia: W B Saunders, 1990.

8 Drury TF, ed. Assessing physical fitness and physical activity in populationbased surveys. (This is a splendid collection of papers on the state of the art.) Hyattsville, Maryland: Department of Health and Human Services, 1989. DHHS Publ No (PHS) 89-1253.

9 Public Health Reports, Vol 100, No 2, March-April 1985. Public health aspects of physical activity and exercise. Again, an essential collection of papers by American authorities in this field. Washington DC: US Department of Health and Human Services, 1985

10 Collins KJ, ed. Handbook of methods for the measurement of work performance, physical fitness, and energy expenditure in tropical populations. Paris: International Union of Biological Sciences, 1990.

11 Patrick JM, Bassey EJ, Irving JM, Blecher A. Fentem PH. Objective measurements of customary physical activity in elderly men and women before and after retirement. $\mathcal{F}$ Exp Phys 1986; 71: 41-58.

12 Armstrong N, Balding J, Gentle P, Kirby B. Patterns of physical activity among 11 to 16 year old British children. BMf 1990; 301: 203-5.

13 Shectman KB, Barzilai B, Rost K, Fisher EB. Measuring physical activity Shectman $\mathrm{KB}$, Barzilai B, Rost K, Fisher EB. Measuring phys
with a single question. Am $\mathcal{f}$ Public Health 1991; 81: 77-3.

14 Shephard RJ, Allen C, Benade AJS, et al. The maximum oxygen uptake-an international standard of cardiorespiratory fitness. Bull WHO 1968; 38 : $757-64$

15 Astrand PO, Rodahl K. Textbook of work physiology. New York: McGrawHill, 1986.

16 Bouchard C, Lesage R, Lortie G, et al. Aerobic performance in brothers, dizygotic and monozygotic twins. Med Sci Sports Exerc 1986; 18: 639-46.

17 Rao DC, Morton NE, Glueck CJ, Lasarzewski PM, Russell JM. Heterogeneity between populations for multifactoral inheritance of plasma lipids. Am f Hum Genet 1983; 35: 468-83.

18 Lamb KL, Brodie DA. Leisure-time physical activity as an estimate of physical fitness: a validation study. $f$ Clin Epidemiol 1991; 44: 41-52.

19 Sobolski J, Kornitzer M, De Backer G, et al. Protection against ischaemic heart disease in the Belgian physical fitness study: physical fitness rather than physical activity? Am $\mathcal{f}$ Epidemiol 1987; 125: 601-10.

20 National Fitness Survey, England. Reports, 1992 (forthcoming). 